\title{
Denoting Offence
}

\author{
Carl Vogel \\ Computational Linguistics Group \\ Centre for Computing and Language Studies \\ School of Computer Science and Statistics \\ Trinity College Dublin \\ Dublin 2, Ireland \\ vogel@tcd.ie
}

\begin{abstract}
A framework for articulating formal semantic theories of linguistic politeness and impoliteness is provided. A theory of (im)politeness is developed within this framework. This builds on recent argument that (im)politeness behaviors arise from offence management associated with disgust.
\end{abstract}

Keywords: politeness, impoliteness, offence, disgust, semantics, pragmatics

\section{Introduction}

Linguistic politeness and impoliteness may be fruitfully studied from the perspective of formal semantics. It is common to reflect on (im)politeness behaviors in a wider category than those achieved using linguistic means. Focus on linguistic (im)politeness is not necessarily to the exclusion of politeness in general. However, because it is sometimes argued that there is no inherent politeness or impoliteness in linguistic expressions, with the general argument that pragmatic theory, rather than semantic theory, is required to provide a productive analysis of the phenomena, if one is able to demonstrate that a semantic theory is available for linguistic (im)politeness then one is able to advance the field, if only by clarifying it. ${ }^{1}$

A formal semantic theory of linguistic politeness and impoliteness is one which can state in precise terms what is meant by expressions regarded as polite: in a truth-conditional setting this means articulating the constraints on the world which would have to be in place for relevant expressions to be deemed true or false, polite or impolite. If the semantics is compositional, then these qualities of larger utterances can be determined from the meaning contributions of their parts. As a semantic theory, such an analysis makes predictions about the interpretation of compositionally related items, given the interpretations of expressions they depend on. If it turns out that the means of articulating the

\footnotetext{
${ }^{1}$ Some [40] argue that pragmatic theory is also inadequate, that a theory of (im)politeness is impossible; in this case, what is studied are the communicative contexts and whether the participants in those contexts experienced politeness or impoliteness - this is the "discursive" approach.
} 
constraints on the world which have to be in place in order for an utterance of a sentence to be evaluated as true and impolite also provides a reasonable characterization of what makes certain non-linguistic behaviors in the same situations also be deemed impolite, then the semantic theory provides an effective interface to pragmatic theory.

The aim of this article is to spell out such a semantic theory. One of the values of this exercise, a mechanization of politeness, is that once one has an appropriate framework in place one may incorporate it into the system that manages communicative behaviors in robot interactions. While linguistics may have functioned well without a semantics for linguistic (im)politeness for a long time, when it comes to interacting with robots, the practical benefits of mechanizing politeness are more clear. People tend to prefer to interact with polite individuals over impolite individuals. ${ }^{2}$

The semantics theory developed here is informed by the view that politeness and impoliteness behaviors are manifestations of offence management, offence rooted in disgust [38]. ${ }^{3}$ This can be understood as a converse emphasis to that sometimes offered for (im)politeness. For example, in an influential analysis [27], the rules of politeness are phrased in the positive, effectively as in Maxims 1-3.

Maxim 1 Avoid imposition. (Lakoff)

Maxim 2 Provide options. (Lakoff)

Maxim 3 Make interlocutors feel good. (Lakoff)

In contrast, the focus here is more aptly characterized by a principle of politeness guided by Maxim 4, and impoliteness guided by Maxim 5 (where ways to feel bad are to feel disgusted or disgusting).

Maxim 4 Avoid seeming bad. (Politeness)

Maxim 5 Make interlocutors feel bad. (Impoliteness)

The focus here on offence rooted in disgust as an explanation of politeness behaviors does not deny that other forms of offence exist nor deny that emotive responses comparable to disgust figure into the offence management argued to shape (im)politeness. Rather, it is argued that the human disgust response is so comprehensively powerful in comparison to other emotions that it gives the best explanation of why politeness behaviors exist, even if those behaviors may be co-opted to manage offence related to other emotive responses as well. Some argumentation from related work [38] is repeated here, particularly in $\S 2$, where the role of disgust in (im)politeness is argued. In $\S 3$ a theory is proposed of predicates made true by observations entailed by the experience of offence. This

\footnotetext{
${ }^{2}$ This does not deny the appreciation felt for Groucho Marx types, or that some appear to relish having a persistently rude foil.

${ }^{3} \mathrm{I}$ contrast this with offence rooted in aggression $[4,9,10,25,26]$.
} 
theory is elaborated in $\S 3.1$ in which additional predications of events are described in relation to offence and the interpretation of (im)politeness. The way theory anticipates (im)politeness behaviors is indicated in $\S 3.3$, and interpretation of (im)politeness is described in $§ 3.4$. Finally, concluding remarks show how this approach provides insights into some of puzzles related to politeness.

\section{Disgust}

The relation argued between (im)politeness behaviors and offence management is illuminated with focus on disgust as a root of offence. The human disgust response has been argued to be a behavioral universal [14] among humans that is not shared with other animals [24]. Features of the disgust response can be highlighted by comparing memories of moments when one has been disgusted with one's experience in immediate response to the depiction in Fig. 1. Firstly, in spite of the relativistic terms of the example, which are meant to allow for the relativity of disgust triggers ${ }^{4}$ in contrast to the universality of the disgust response, most readers are unlikely to imagine what the picture in Fig. 1 would be for them, certainly not on immediate on reflection, and possibly only after extended consideration. This is an example of disgust avoidance: its pressure is such that people avoid constructing mental images of the worst triggers. Evidence that the most upsetting possible image was not constructed is in the absence of the primary symptoms of the disgust reaction. These include reflexes of expulsion, such as triggered by ingested toxins, avoidance, as of signs of disease and parasites, and arousal of the sort experienced during anger, such as triggered by the threat or reality of harm. A canonical manifestation of the response is nausea and nausea-sympathetic oral and nasal musculature reflexes. While nausea is not necessarily visible to witnesses, the latter are. The primary response is involuntary and not intended as a signal, but merely the consequence of nauseasympathetic reflexes. ${ }^{5}$ The immediate response is followed by the sensation of pollution and desire to purge the contamination.

An insightful description of disgust responses and a theory of their evolution is provided by [24]. A main feature is that disgust responses are involuntary. Disgust triggers are, perhaps uniquely, available to "one-shot" learning: one never

\footnotetext{
${ }^{4}$ Disgust triggers, like fear triggers, are relative: recall a passage from Orwell's 1984 just as a starved rat is being configured to have access to Winston Smith's face: "The worst thing in the world,' said O'Brien, 'varies from individual to individual."' [32, p. 233]. The disgust response differs from the fear response variously [25]: for example, protective bars between an experiencer and a fear trigger such as a rabid dog will be sufficient to allow an experiencer to be in a close degree of proximity without fear, but would not be a sufficient prophylactic against a disgust response to a disgust trigger. Similarly, disgust differs from anger, which can subside relatively quickly even in the presence of an experiencer and its trigger; disgust tends not to subside.

${ }^{5}$ Nonetheless, as a consequence of shared embodiment, it is readily available for interpretation by witnesses, and therefore a very effective sign when used voluntarily, even metaphorically.
} 
Fig. 1. A superlatively upsetting image

This is a picture of the
most disgusting thing
you can imagine.

forgets the sort of food item it was that one holds responsible for a single episode of food poisoning, and this can create a permanent aversion. ${ }^{6}$ The response to disgust triggers is as if they have the power to contaminate the environment. Upon encounter with a disgusting substance, one feels compelled to seek cleansing and purification. Items that have been in contact with the disgusting item may themselves be discarded rather than treated, because of the sensation that the contamination is contagious. Further, the contamination is overwhelmingly irreversible. $^{7}$ The contamination easily associates with related objects and individuals. Where disgust arises from the manifestations of decay and infection associated with disease, people have historically found it difficult to accept as uninfected those who have associated with the visibly infected. ${ }^{8}$ It is through the capacity for transfer of disgust through contamination that the response generalizes from biological triggers (rotting life forms, toxins, bodily excretions) to associates whose availability depends on situations of encounter that yield the possibility for culture-specificity of triggers (whether in dinner menus or "moral" choices). This is because people who share a social and geographical niche are more likely to have experiences in common, including both situations that invoke disgust and accidental properties of those situations to which the disgust response generalizes. It is through the propensity for situations of disgust to be perceived as contaminating associates, contaminating inanimate objects and human beings alike, that (im)politeness behaviors become relevant to social interactions and worth the energy they require: if one can project the image of politeness, one can mitigate other triggers of disgust within one, and if one is

\footnotetext{
${ }^{6}$ The contrast in learning speed in other dimensions of human development merits reflection. Other cognitive reference points are the speed of language acquisition, in the general absence of labelled negative examples, and the slow pace of mastery of valid reasoning [22]. Episodic recall triggered by smell appears to be a corollary.

7 Introspection into one's own experience of physical disgust or reflection on reports from others is likely to confirm the observation that physically effective cleansing, to the point of sterilization, is not psychologically effective; rather, somewhat irrational symbolic cleansing rituals are necessary as well in the cases where reversibility is possible. Consider separation and re-use of household cleaning rags dedicated to various surfaces, or how universally disinclined people are to accept food for consumption from dishes used in the past to serve pets, and so on.

8 The associations need not follow a rational course. We live in a society in which a medical doctor who manually conducts prostate examinations is accorded more esteem than a person who works in garbage collection, even though both may be safely assumed to engage in appropriate levels of hygiene and though the garbage collector probably has a greater overall positive impact on health in society.
} 
disgusted by someone, who is therefore (by definition) threatening, then one has reduced need to avoid impoliteness.

As physical disgust responses are available for interpretation, they themselves are available for adaptation and re-use as conscious signals. The availability of the response for generalization predicts "metaphorical" extension to triggers that are not associated with toxins or disease - social triggers, for example. Contempt and disgust involve comparable affective states, and are frequently both apt descriptions of the same affective states, but are not identical in their use conditions. One may think of contempt as a socially mediated form of disgustthe sort of feeling invoked by someone who harms other people for sport (which might be experienced without qualm by someone who declares sport-fishing as a hobby). Here again, people are inclined to form an ill opinion of associates of those for whom they feel contempt. In the extended sense, relative irreversibility of the attribution is likely: as the aphorism goes, trust takes years to build and seconds to break. The role of disgust in social situations, as opposed to situations with immediate physical triggers, is also evident in the fact that in some moral debates some will attempt to argue the correctness of one position over another on the strength of the disgust response. Indeed, some are tempted to resolve questions of morality with reference to disgust responses that are triggered by the behaviors associated with the moral questions, ${ }^{9}$ and it is the fact that accidental association is fundamental to disgust that makes appeal to disgust unsafe as a justification for a moral judgement [24]. Nonetheless, the power of disgust contagion to include moral and social issues is frequently exploited in rhetorical moves intended to sway opinion within public discourse.

These considerations lead to the claim that the potential irreversibility and contagiousness of disgust responses are what prompt (im)politeness behaviors, despite the communicative expense of producing them. With respect to politeness behaviors, where not overused to the point of obsequiousness, they provide a mechanism for avoiding being deemed disgusting. They offer rituals for rectifying social mistakes. Where consistently applied, they offer a shield against premature criticism in the face of disgust triggers, where those disgust triggers are then deemed "out of character". These behaviors have also been generalized as "politic" [40]. On this view, impoliteness behaviors are produced when the impolite actor views their interlocutor with disgust. Perceived asymmetry for the impolite actor allows that person to believe that by being impolite they will not attract disgust but will instead lead the target of their action to be viewed with disgust by any witnesses. Of course, a risk of impoliteness is that public perception will be the opposite. However, impoliteness behaviors themselves amount to the proof that the agent believes either that witnesses will also view the target with disgust or that the witnesses are themselves worthy of contempt and do not merit civility either.

\footnotetext{
${ }^{9}$ In June 2013, a Google search of the web for the phrase, "wrong because it is disgusting", with quotation marks and without any specification of what "it" might refer to, yielded 768,000 hits.
} 


\section{Semantics of (im)politeness}

The discussion so far suggests that a model of disgust management is necessary to the interfaces of politeness theory. The facts that such offence is amenable to one-shot learning and that the disgust response has a visceral element speak to its fundamental importance. The generalization of the response to associates (and even to the experiencer) creates an inherent risk of ostracism through disgust responses in the community. Therefore, a mechanism which mitigates disgust responses and averts such risks, where possible, has a self-preservation function. Politeness emerges as a manifestation of that mechanism in social interactions, and impoliteness, as a purposeful re-use of the mechanism. The explanation offered here is more general than the notion of "facework" as preservation of public personae and freedom of action [7]. A model of offence management must have the capacity to encode responses to events and the entities that participate in those events.

Offence arising from disgust appears to be vividly located in particulars, even though it is open to generalized reaction to types. Nonetheless, it is natural to model the offended reaction to disgust in both cases as anchored in particulars: either some event is constituted by sub-particulars that elicit the disgust reaction, or some event that involves reflection on types that create offence in the attitude of the reflecting agent, this reflection event itself constituting a particular. In a three-valued model, agent observation of all particulars triggers disgust, triggers attraction, or is neutrally in between. This model of observations entails that any observation $o$ further specifies the type of $\hat{o}$, the attitude of the speaker in the spectrum from offence to affinity - this spectrum is encoded here as a disjunction (1). ${ }^{10}$ The model is relative to an event particular $(e)$ and the participants in that event (categorized here according to grammatical person; however, this is too coarse-grained, as where there plural values, some subsets for any grammatical person may elicit disgust while others are integral to attraction). ${ }^{11}$ The polarities in the model refer to the three-valued possibilities for offence as generalized disgust. ${ }^{12}$ Further, the disgust response involves a change of state, with potentially different polarities accorded to each grammatical person before, during and after the triggering event.

${ }^{10}$ If the attitude taken by the agent is one of disgust, then it is natural to think of $o$ as encoding offence. Thinking of it as relative offence, is helpful so long as it is remembered that all three of the possible values are viable.

11 Additional constraints on events assumed by this model are outlined below (3).

12 An infinitary valued system of gradience could also be modelled; however, I propose to establish the limits of a three-valued system before exploring alternatives. 
$(1) \hat{o}(e)={ }_{\text {attitude }}\left[\begin{array}{rl}\text { person: } & \text { polarity } \\ \text { before- } e:\left[\begin{array}{ll}\text { 1st: } & 1 \vee 0 \vee-1 \\ 2 \mathrm{nd}: & 1 \vee 0 \vee-1 \\ \text { 3rd: } & 1 \vee 0 \vee-1\end{array}\right] \\ {\left[\begin{array}{ll}\text { person: } & \text { polarity } \\ \hline 1 \text { st: } & 1 \vee 0 \vee-1 \\ 2 \mathrm{nd}: & 1 \vee 0 \vee-1 \\ 3 \mathrm{rd}: & 1 \vee 0 \vee-1\end{array}\right]} \\ \text { after- } e:\left[\begin{array}{ll}\text { person: } & \text { polarity } \\ \text { 1st: } & 1 \vee 0 \vee-1 \\ 2 \mathrm{nd}: & 1 \vee 0 \vee-1 \\ 3 \mathrm{rd}: & 1 \vee 0 \vee-1\end{array}\right]\end{array}\right.$

Prior to consideration of intervening events, it is possible that a default evaluation holds in the mind of the speaker with respect to interlocutors in a dialogue situation, ${ }^{13}$ a default in which none are considered negatively, and with a positive self-evaluation on the part of the speaker (2).

attitude $\left[\begin{array}{lc}\text { person: } & \text { polarity } \\ \hline \text { 1st: } & 1 \\ \text { 2nd: } & 0 \\ \text { 3rd: } & 0\end{array}\right]$

This equation specifies a default instantiation: appropriate frameworks for defaults in feature logic are available [28].

Using the model, when extreme values obtain, follow-on reactions by the reflecting agent may be anticipated, depending on other constraints that are in effect at the time. This is developed further in $\S 3.2$, after more detail about the assumptions about events required by a semantic theory of (im)politeness.

\subsection{Properties of events}

A semantic theory of (im)politeness must take into account the speaker's evaluation of events and agents participating in them. When speakers utter sentences, events are described, and some elements of the event description is partially encoded directly in the syntax/semantics interface (e.g. tense [34] and aspect [37]) while other elements of meaning associated with an expression about an event follow from inference from the fact that the particular described event is of a certain type [11]. The evaluation of events undertaken by speakers includes an abstract assessment of costs and benefits.

Events may be treated as particulars, instantiations of types [11]. A view of events as particulars goes a long way in addressing some of the contingencies of pragmatics involved when some instances of an event type but not others give rise to offence. As a particular, an event $e$ makes relevant relations true among arguments and has certain other properties. Some of the properties that hold

$\overline{13}$ A dialogue situation is a focused interaction in Goffman's terms [19, p. 24]. 
of an event $e$ may predicted from the fact that it is an instance of a type $\hat{e}$. For example, events have temporality: they are located in time, past present or future; they have aspect, the composition of the verbal relation for the duration that they hold; they have mode, realis or irrealis. Any event particular will fix values for these, as appropriate to the level of granularity with which it is viewed. The view of events here is sympathetic to formal models of tense and aspect that make much of the variable granularity with which one (as a semantic theoretician, or as a speaker) may observe events unfolding [15]. Events may also be thought of as having proto-agents. It is convenient to adopt the terms syntactic person to characterize the proto-agent of an event: it is either a first, second or third person agent, the final serving as impersonal, as well. Events that are commented upon by speakers have both value and cost. The value for each of the three persons is, in principle, independent, even if often aligned. The same holds of costs. A simple calculus of use and cost may use a three-valued polarity system with 1 representing positive value, 0 representing neutral value, and -1 representing negative value. A comparable model is available for costs, which can be subtractive (-1), neutral (0) or involve gain (1).

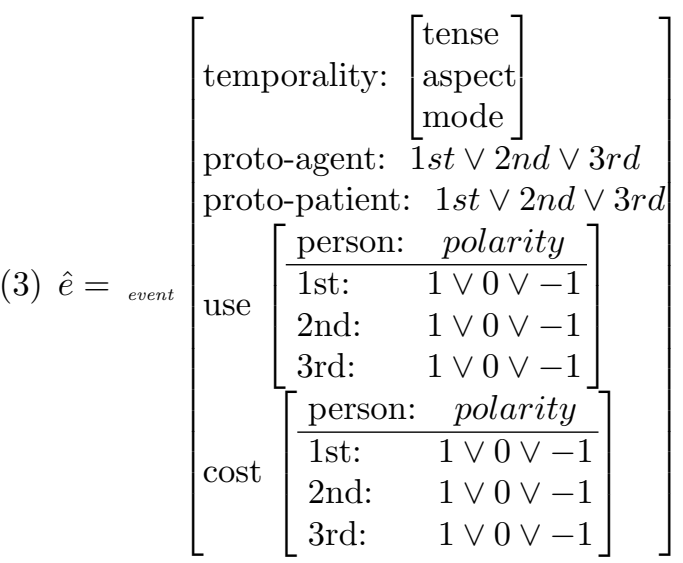

Dialogue proceeds as each interlocutor assumes the role of speaker. ${ }^{14} Q u a$ speaker, that interlocutor makes a decision about what event $(e)$ or event regularity to comment upon. If it is an event particular, it might be an event that none of the interlocutors participate in, or it might be the immediately preceding (or even currently unfolding) contribution to the dialogue. Additional to the other qualities of the event that require the agent to make compositional decisions (e.g., predicate selection, argument structure and alternations; cf. [13,31]), the speaker makes conclusions about how $e$ resolves $\hat{e}$. An event type $\hat{e}$ might might be instantiated in any of the possible combinations that resolve each of its disjunctions. An event $e$, located in the past, with a first person proto-agent might figure into an apology. If the event $e$ is located in the future, with a second

\footnotetext{
14 There is a subtle difference between "assuming the role" of speaker and "taking a turn" as a speaker: the latter suggest that the speaker has unique control over the floor for the duration of the turn, while the former lacks that suggestion.
} 
person proto-agent, the utterance might unfold as a request. If the event $e$ is located in the present, continuous, with a third person proto-agent, the utterance may turn out to be a comment on the weather, in bus-stop chatter.

Alternatives are selected on the basis of the speaker's perspectival observation $o$ of $e$ in relation to the agents involved in the event and the discussion. The net value for each person combines use and cost; see Table 1 for one possible specification of the combination of values of use and cost to yield net values.

Table 1. A specification of net offence/affinity as a function of use and cost

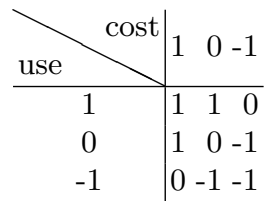

The (im)politeness to be expressed by speaker $S$ is conditioned by $e$ and $o$. Conversely, a statement that is construed as impolite or polite entails that certain constraints from $\hat{e}$ and $\hat{o}$ are resolved in particular ways. The default semantics of some expressions is polite, and of others, impolite. Like any others, these defaults may be over-written by more specific information.

\subsection{Offence management}

The functions that require a model in a theory of offence management are those that further specify $\hat{o}$. Consider the conjunction $(\alpha \wedge \beta)$ of feature-value path equations (4.a) and (4.b) describing sharing of features and values in the instantiations of attribute-value matrices (see [23] or [8]). ${ }^{15}$ The constraint (4) models the level of offence attributed to the agent $(\mathrm{i})$ of an event by a speaker reflecting on the event as identical to the net offence $(j \mathrm{j})$ of the event for the speaker (who may or may not be the proto-agent). The principle is agnostic to whether the outcome is disgust or delight as well as to whether the proto-agent is the speaker or not. However, it makes a clear statement that the proto-agent of the event is held responsible, as opposed to the proto-patient. ${ }^{16}$ An asymmetry may exist that mirrors the asymmetry in the syntax and semantics of raising verbs in that, cross-linguistically, there are fewer verbs that allow the syntactic object of an embedded clause to "raise" to a subject position than allow subjects from embedded clauses to appear in semantically equivalent sentences with the embedded subject as outer subject (see $\left.(5)^{17}\right)$. Most event descriptions in English,

${ }^{15}$ Unless disambiguated, assume implicit existential quantification over indices: $\exists \mathrm{i}, \exists \mathrm{j}(\alpha \wedge \beta)$. Duplicated indices indicate co-reference, shared values.

${ }^{16}$ In a reflexive event, the proto-agent is identical to the proto-patient.

17 The prefixed symbol $\left(^{*}\right)$ is used to indicate ungrammaticality. 
and in most socio-economic groupings, are such that the evaluative outcome fits the constraint in (4) rather than (6).

(4) Blame/Praise the agent. $(\alpha \wedge \beta)$

a. $\alpha \equiv e$ :proto-agent $=\mathrm{i}$

b. $\beta \equiv \hat{o}(e)$ :after-e:person: $\mathrm{i}$ :polarity: $\mathrm{j}=e:$ net:1st:polarity: $\mathrm{j}$

(5) a. It appears Leslie likes pineapple

b. Leslie appears to like pineapple.

c. *Pineapple appears Leslie to like.

d. Pineapple appears easy for Leslie to like.

(6) Blame/Praise the victim. $\left(\alpha^{\prime} \wedge \beta\right)$

a. $\alpha^{\prime} \equiv e$ :proto-patient $=\mathrm{i}$

b. $\beta \equiv \hat{o}(e)$ :after-e:person: $\mathrm{i}$ :polarity: $\mathrm{j}=e:$ net:1st:polarity: $\mathrm{j}$

The propensity for disgust to be perceived as contagious is captured by the sharing of the minimum value of the offence level, conditioned on that being the level that represents disgust (-1); thus, the constraint (7.b) should be thought of as conditioned upon $\mathrm{k}=-1$. If the constraints of (7) hold without such conditioning, then the formula describes the theory that low estimations and not just attributions of disgust are subject to contagious transfer. ${ }^{18}$

(7) Contamination spreads
a. $\mathrm{k}=\operatorname{MIN}\{\mathrm{j} \mid \exists \mathrm{i}, \hat{o}(e)$ :after-e:person: $\mathrm{i}$ :polarity: $\mathrm{j}\}$
b. $\forall \mathrm{j}, \hat{o}(e)$ :after-e:person: $\mathrm{i}$ :polarity: $\mathrm{j}=\mathrm{k}$

The provision of the model $(\hat{o})$ addresses the essential nature of offence management since it provides a locus for specifying the effects. Additionally, it provides an interface to other aspects of linguistic expression and other behaviors. This is expanded upon next.

\subsection{Predictions}

It appears safe to make predictions on the basis of certain further instantiations of $\hat{o}$ and the $\hat{e}$ it depends on. For a speaker, (im)politeness at any turn is conditioned by the interaction of: the net value of the event described, $e$, and the attitude, $o$, towards relevant individuals: self, hearer, and others. The predictions relate to the follow-on behavior of the speaker. Below, $\theta$-polarity refers to the final value within $\hat{o}$ for the corresponding grammatical person or the proto-agent of the triggering event $(e)$. The defaults (9-12) characterize reasonable expectations of how the speaker might intend to react to the event $e$ being spoken about when assuming the role of speaker. Here, "reasonable" is taken in the spirit of

${ }^{18}$ It would be constructive to explore the relationship between this version of the negative contagion principle applied to agents and the processes of pejoration in language change, through which, for example, "hussy" ceased suggesting respectability $[3,16]$. 
the "reasonable man" as used in jurisprudence, however problematic that notion may be $[12,2]$. As a general default, one would imagine that speakers will make a response that is unmarked with respect to politeness. This may amount to generally using linguistic forms that convey politeness, but it needn't. In unmarked situations, is is natural to assume that the speaker's self-reflexive attitude as a polarity that is positive, and equal to the speaker's attitude to other interlocutors. ${ }^{19}$ Thus, the principles in (9-12) characterize marked situations, where the speaker has distinctive attitudes.

(9) If 1st-polarity < 2nd-polarity, expect politeness

(10)If 1st-polarity $>$ 2nd-polarity, expect impoliteness

(11)If 1st-polarity < proto-agent $(e)$-polarity, expect politeness

(12)If 1st-polarity $>$ proto-agent $(e)$-polarity, expect impoliteness

Inspection of these principles reveals that they may yield directly conflicting expectations, since the addressee need not be the proto-agent. The first (9) is triggered when the speaker has a greater estimation of the person addressed than self-estimation, and the triggered expectation is of a politeness behavior. The last (12) yields a conflicting expectation that the speaker's utterance will express impoliteness where the speaker's self-estimation exceeds the speaker's estimation of the proto-agent of the event being commented upon, who may be a third-party. This can happen where an event of the sort characterized below (13) gives rise to the differential attitudes described (14). The event type (13) is one in which the use is unspecified for the speaker, non-negative for the addressee and non-positive for third parties; it is one in which cost is similarly specified: the addressee is assigned no loss nor third parties any gain. An attitude that a speaker may take with respect to those values is indicated (14). The cumulative expectation arising from this attitude is a mixed message of deference to the addressee and disdain for the third party, as a function of the corresponding $\theta$ polarities. As a result of the distinct signals, observers of any resulting utterance may be divided with regard to whether the utterance was polite or impolite.

19 This sentence describes a more generous default possibility (8) than the earlier one $(2)$.

(8) attitude $\left[\begin{array}{lc}\text { person: } & \text { polarity } \\ \hline \text { 1st: } & 1 \text { i } \\ 2 \mathrm{nd}: & \mathrm{i} \\ 3 \mathrm{rd}: & \mathrm{i}\end{array}\right]$ 


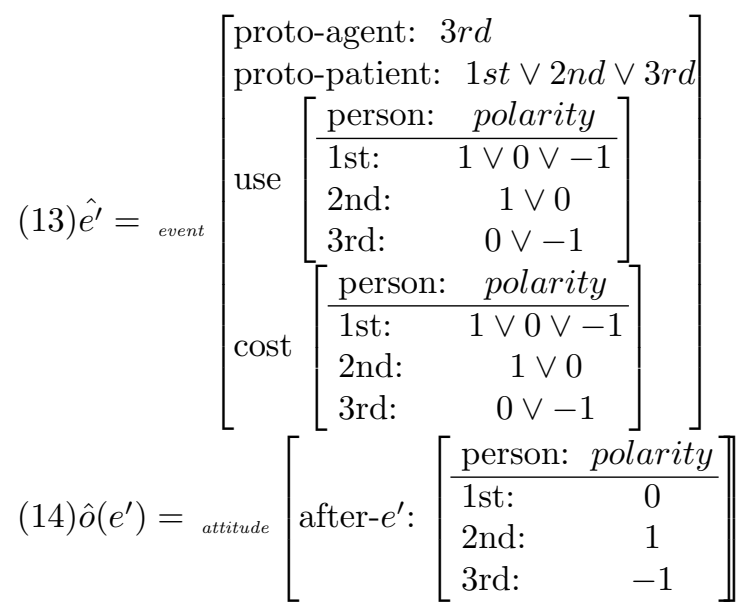

Again, a triggering event may be an external world event or a conversational event within the dialogue. Construals of events and attitudes is dynamic. This section has made reference to behaviors that may be expected on the basis of agent classification of events and net attitudes towards other agents. The agent has been referred to as speaker at times; however, non-linguistic behaviors may be triggered as well as linguistic behaviors.

\subsection{Interpretation}

In the other direction, one may infer from (im)polite language, signals through other communication modalities, or overt behavior corresponding further specification of $\hat{o}$ and $\hat{e}$. The main focus here is on interpreting linguistic expression. This is the sense in which a semantic framework for politeness is provide here. The framework is incomplete in that complete details of compositionality are not provided, even though some elements of this are sketched. It is clear that these details must ultimately take into account means of modulating affect additional to that supplied through lexical semantics, for example prosody and volume.

(15)Salt.

(16)Scalpel.

If all one knew about a context of interaction was that someone uttered (15) as a means to obtaining salt from a fellow-diner, one would likely consider the speaker rude. In contrast, representations in popular entertainment of medical surgery would yield an impression of the speaker of (16) in a comparably decontextualized operating theatre that would not be specified for rudeness (except to the extent that one thinks of surgeons as rude, by default). The contrast between (15) and (16) demonstrates the role of context in determining attributions of rudeness: the default for a request for salt is use for one's own consumption, while the default for a request for a scalpel is use for primary benefit that is not one's own. A pragmatic politeness principle of selflessness may be stated 
as in (17). ${ }^{20}$ This is a principle with force beyond linguistic communication. ${ }^{21}$ Attributions of politeness, therefore, transcend language.

(17)a. Putting oneself before others is impolite.

b. Putting others before oneself is polite.

It seems that in contemporary society, fulfilling 17.a triggers the generalized cultural disgust response, and thereby violates Maxim 4 and satisfies Maxim 5; while fulfilling 17.b satisfies Maxim 4.

The force of the politeness principle (17) is that it allows interpretation of the examples $(15 \& 16)$ as providing further specification of the attitude $(\hat{o})$ of the corresponding speakers. Putting one's own needs ahead of the needs of others, at a dinner table (15), without explicit effort to mitigate the possibility that this will be elicit a disgust response, constitutes evidence that, all else equal, one has a higher estimation of oneself than the person one is addressing. This interpretation results in constraints on the described event (18.a,18.b). In contrast, with respect to defaults, the operating theatre utterance (16) may lead to the conclusion that balanced attitudes are in place (19.a,19.b).

(18)a. $\hat{o}\left(e^{\prime \prime}\right)={ }_{\text {attitude }}\left[\right.$ after- $e^{\prime \prime}:\left[\begin{array}{ll}\text { person: } & \text { polarity } \\ \hline 1 \text { st: } & >-1 \\ 2 \mathrm{nd}: & <1\end{array}\right]$

b. $\quad \hat{o}\left(e^{\prime \prime}\right):$ after- $e^{\prime \prime}$ :person:1st:polarity $>\hat{o}\left(e^{\prime \prime}\right):$ after- $e^{\prime \prime}$ :person:2nd:polarity

(19)a. $\quad \hat{o}\left(e^{\dagger}\right)=_{\text {attitude }}\left[\right.$ after- $e^{\dagger}:\left[\begin{array}{ll}\text { person: } & \text { polarity } \\ \hline \text { 1st: } & 1 \vee 0 \vee-1 \\ 2 \text { nd: } & 1 \vee 0 \vee-1\end{array}\right]$

b. $\quad \hat{o}\left(e^{\dagger}\right):$ after- $-e^{\dagger}$ :person:1st:polarity $=\hat{o}\left(e^{\dagger}\right)$ :after- $e^{\dagger}:$ person:2nd:polarity $)$

Additionally, politeness is amenable to linguistic encoding (20 \& 21), although the exact circumstances of context will determine whether the target audience for the utterances deem them polite or impolite (or speaker intent in the matter). The "please" examples yield constraint that speaker self-estimation does not exceed the speaker's estimation of the addressee (22.a), and the "idiot" examples yield the opposite of that (22.b).

(20)a. Salt, please.

b. Salt, idiot.

(21)a. Scalpel, please.

b. Scalpel, idiot.

(22)a. $\quad \hat{o}\left(e^{\diamond}\right)$ :after- $e^{\diamond}$ :person:1st:polarity $\leq \hat{o}\left(e^{\diamond}\right)$ :after- $e^{\diamond}$ :person:2nd:polarity

b. $\quad \hat{o}\left(e^{\boldsymbol{*}}\right)$ :after- $e^{\boldsymbol{\omega}}$ :person:1st:polarity $>\hat{o}\left(e^{\boldsymbol{\omega}}\right)$ :after- $e^{\boldsymbol{*}}$ :person:2nd:polarity

${ }^{20}$ This is closely related but not equivalent to Leech's maxim of generosity: MINIMIZE BENEFIT TO SELF; MAXIMIZE COST TO SELF [29, p.133].

21 The principle is a strong default. There are conceivable situations in which putting oneself first is arguably better for the community than the alternative. 
This suggests a formulation of the semantic contribution of "please", for example, as in $(23)$ - a function that effectively delivers the set of events for which the attitude of the speaker is that speaker polarity is no greater than addressee polarity. For an imperative, this function may be taken to apply to each in the set of events that could possibly follow the speaker's utterance event in which the addressee makes the predication true, characterizing the speaker's estimation of relative polarity in each.

(23) $\lambda x .[\hat{o}(x)$ :after- $x$ :person:1st:polarity $\leq \hat{o}(x)$ :after- $x$ :person:2nd:polarity]

Further details of interface to a semantic theory of imperatives $[36,33]$ are left unspecified here. However, identifying here how a word like "please" may contribute meaning goes further: while a word may have a meaning, non-linguistic acts may also have the effect of specifying the values of $\hat{o}$ and $\hat{e}$ for an agent, and thus determine whether politeness is attributable to those behaviors.

In discussing linguistic politeness from the point of view of semantic theory, it is methodologically safe to put irony and sarcasm aside: any ironic use of an expression is parasitic upon its default interpretation. The framework presented gives of what may be inferred to be true about the world on the basis of utterances that convey explicit politeness or impoliteness. Truth inferences about the world include inferences about the speaker's attitudes towards interlocutors and perceptions of the personal value of the event being commented upon.

\subsection{Other properties of events}

Discussion above emphasized the temporality of the event described by the speaker's contribution. The event may be located in the past, or the future, or may have an irrealis status as a particular through comment on event types such as in habituals. The sequence of attributions of events required by the model proposed here are available as triggers and explanation of ongoing behavior of agents as they act upon their interpretations.

Differences in an agent's views of the value of some future event for the agent's self may lead an utterance about that future event to take the form of a polite request or as an order. Attitudes towards interlocutors and their role in a past event under discussion, may, also in relation to the use for the speaker, lead to an apology or to an affronted self-justification. Thus, a semantic theory of politeness must allow that from the classification of an utterances as polite or impolite that a corresponding configuration of esteem for interlocutors and value of the event for the speaker is in place.

\subsection{Summary}

In this section a formal semantic theory of (im)politeness has been offered. One might approach the preceding discussion as if what is introduced is a formalism for specifying semantic theories. Indeed, a framework is presented, but within that framework, a theory has been provided which makes specific claims about 
the interpretation of linguistic politeness and impoliteness. Any compositional truth-conditional semantics contributes to the theory of meaning by specifying conditions in which given sentences are true. Here, a compositional syntaxsemantics interface has not been sketched, but predications that are true or false in particular events have been described as the semantic contribution of utterances conveying (im)politeness. If a sentence is taken as polite, then conditions such as (22.a) are true, and if impolite, conditions like (22.b) are true.

\section{Concluding remarks}

One might wonder why linguistic politeness exists at all, given that it requires communicative effort, and since it has little value in private thought. It is noteworthy that in other dimensions of language use, a tendency towards reduction of effort is palpable. After topics and entities are introduced into discourse they are typically referred to subsequently with definites with reduced descriptions and ultimately pronouns that exhibit phonological reduction [17,21]. Even in the context of such reductions, politeness terms persist. This represents an uncommon level of linguistic effort. This article has argued a position on why (im)politeness forms are given the energy they are by interlocutors-the gist of this position is that the mechanisms of disgust and offence are powerful and pervasive and that (im)politeness behaviors arise as investments in mitigating disgust responses.

It is easy to find in the literature emphasis on the role of pragmatic context in politeness evaluation $[1,40]$. While some have argued the impossibility of semantic analysis of (im)politeness [40], others also emphasize that forms of language associated with politeness expressions are open to systematic semantic analysis [10]. Among those who emphasize the relativity of politeness judgements, researchers who appeal to the norms of language use in a community of practice as determining what counts as polite or impolite implicitly rely on straightforward interpretation decoding content and politeness levels of utterances within those sub-languages (e.g. [35]). The formulation of the semantics, as opposed to the pragmatics, of linguistic politeness has remained an open problem.

Past theories of (im)politeness of tended to focus on the pragmatics of politeness. Inspired by Goffman's analysis of human interactions in terms of "face" $[18,20]$, the research programme of a large part of the literature was defined by a view of politeness as "facework" [7]. On this conception, two construals of the self influence the perception of actions as polite or not: positive face, self-image held in unison with others' image of self; negative face, freedom to act. An alternative view does not emphasize the self in isolation as much as through relation management, and in this conception, politeness is seen as "relational work" [30, 6 . The view pursued here is not at odds with either of those conceptions, which themselves appear to be complementary rather than competing frameworks for analysis, but attempts on one hand to contribute to explanation the perception of acts as polite or impolite and on the other hand to specify the ontology required in order to deliver a formal semantics for linguistic politeness and im- 
politeness. An independent test of the efficacy of this proposal is the extent to which it addresses some of the puzzles of politeness and impoliteness, such as those described already, or additional puzzles, like the interaction of familiarity on perception or production of the relevant behaviors.

Linguistic politeness is a species of politeness behavior. Linguistic politeness is one dimension of language use that is quintessentially communicative. Even if one agrees that overwhelmingly dominant use of language is for thought, rather than for communication, one must concede that the main role of linguistic politeness is in communicative language use, thinking for speaking, ${ }^{22}$ rather than in thinking for oneself. Notice that thinking for oneself does not necessarily involve anyone else, and therefore the pragmatic politeness principle (17) arguably does not apply. One might think thoughts for oneself that encode negative politeness, but probably not positive politeness: while I can easily enough imagine having thoughts that encode negative politeness (24), I am extremely unlikely to entertain a reflexive thought that encodes positive politeness (25). ${ }^{23}$

(24)Idiot ${ }_{i}$, why did $\mathrm{I}_{i}$ let the toast burn?

(25)\#Carl ${ }_{i}$, please $t_{i}$ enjoy this toast $\mathrm{I}_{i}$ 've made.

With respect to the defaults of interpretation expressed so far, a reflexive thought like the first expression (24) is sensible because it encodes a self-appraisal that is at odds with the default that all are equally held in at least neutral esteem; see (26), where $e^{\Delta}$ corresponds to the described event of the burning of the toast. The oddness of the second example (25) could be explained by the impossibility of signalling greater esteem than is already conveyed in the default discussed above (2) with respect to the situation being evaluated (27). The constraint expressed by the explicit language of politeness cannot be satisfied in this formulation (27.b).

(26)a. $\quad \hat{o}\left(e^{\triangle}\right)=_{\text {attitude }}\left[\begin{array}{l}\text { before- } e^{\triangle}:\left[\begin{array}{ll}\text { person: } & \text { polarity } \\ \hline 1 \text { st: } & 1 \vee 0\end{array}\right. \\ \text { during- } e^{\triangle}:\left[\begin{array}{ll}\text { person: } & \text { polarity } \\ 1 \text { st: } & 0 \vee-1\end{array}\right. \\ \text { after- } e^{\triangle}:\left[\begin{array}{ll}\text { person: } & \text { polarity } \\ \hline \text { 1st: } & 0 \vee-1\end{array}\right]\end{array}\right]$

b. $\quad \hat{o}\left(e^{\triangle}\right)$ :after- $e^{\triangle}$ :person:1st:polarity $<\hat{o}\left(e^{\triangle}\right)$ :before- $e^{\triangle}$ :person:1st:polarity

(27)a.

\begin{tabular}{|c|c|c|}
\hline \multirow{6}{*}{$\hat{o}\left(e^{\odot}\right)={ }_{\text {attitude }}$} & \multirow{5}{*}{$\begin{array}{l}\text { before- } e^{\oslash} \text { : } \\
\text { during- } e^{\ominus} \text { : }\end{array}$} & person: polarity \\
\hline & & 1st: \\
\hline & & person: polarity \\
\hline & & 1 st: \\
\hline & & person: polarity \\
\hline & & 1st: \\
\hline
\end{tabular}

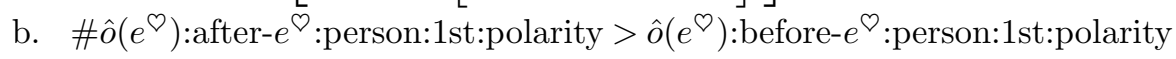

${ }^{22}$ See [31].

${ }^{23}$ The prefixed symbol (\#) is used to indicate semantic infelicity. 
Recalling the proposed semantics for "please" (23), one can also understand why the use of the explicit politeness term may take on a tone of irony when used between intimates via modes of communication like email in which tone of voice does not disambiguate.

(28) $\lambda x .[\hat{o}(x)$ :after- $x$ :person:1st:polarity $\leq \hat{o}(x)$ :after- $x$ :person:2nd:polarity]

(29)Would you take out the trash, please?

That is, among intimates, the polarity estimation conveyed by the expression is already, by hypothesis, common ground. Thus, a redundant assertion of this shared fact, say via an email communication containing just (29) from one to another in a couple, given that people tend not to utter obvious truths (comments on the weather notwithstanding), can easily be taken as indicating its negation, as with other ironic expressions.

One might try to explain the linguistic encoding of politeness by virtue of the transcendence of politeness over language. The argument would be that it is a palpable feature of communication (regardless of the medium), and as a real-world phenomenon, it merits linguistic manifestation. However, this begs the question of why politeness is a feature of human interaction. My argument is that politeness is a form of offence management: humans are polite and use polite expressions in order to avoid invoking disgust; speakers are impolite when they do not object to disgusting others, typically when their evaluation of others is as relatively low in affinity. This view of politeness conveyed by linguistic forms is independent of intent. The politeness value of any expression may vary for speaker, addressee or wider audiences, just as interpretation of language in general may yield distinct meanings depending on who is interpreting it. A theory of (im)politeness can unfold partly in the realm of semantics.

Earlier it was claimed that providing a formal semantics for (im)politeness may contribute to enhancing human-robot interactions. This follows from the informational value of inference from the use of polite or impolite expressions. A mirror to the semantic contribution of "please" (23) is in the semantic content of a second-person utterance of "idiot" (30). ${ }^{24}$ The denotation of an offensive epithet is the set of events characterized by the speaker as involving greater net speaker-polarity than addressee-polarity, and the meaning includes all the entailments that follow from those event classifications. ${ }^{25}$

(30) $\lambda x .[\hat{o}(x)$ :after- $x$ :person:1st:polarity $>\hat{o}(x):$ after- $x$ :person:2nd:polarity]

If a robot is able to attribute to a human interlocutor the belief that the human has a negative net estimation of it, then the robot is in a position to trigger procedures to attempt to understand how this has happened (if it has not always been so) and to rectify the situation, more or less as a human might when

${ }^{24}$ Notice that "please" is not a nominal used predicatively, as "idiot" is in the example. These formulations do not exhaust the semantic contribution of "please" or "idiot". Further, at the level of specification in (30), "idiot" is a synonym of "scum", but there are additional lexical semantic contributions from both words that separate their full meanings.

${ }^{25}$ Meaning is more than denotation. 
preferring to defuse conflict situations over escalating them. It would also be in a position to anticipate some of the logical consequences of the situation and attempt to avert them, as an alternative to trying to understand how the situation arose, or may choose to escalate the situation, again, reflecting on the choice as a human might. With a deeper supply of information about ongoing communication and interaction, more choice is available. Grasp of predicates regarding attitudes to all parties to a situation of communication and the time course of those attitudes is additional to grasp of the lexical semantics of words used in interactions, and this additional information associated with (im)politeness, is information inherently related to communication (as noted above, when pointing out that the language of politeness is more relevant to the use of language for communication than its use in private thought). Attending to the meaning of (im)politeness may therefore constructively inform dialogue planning modules.

The theory sketched here has omitted most details about a syntax-semantics interface for linguistic (im)politeness. Equally, the theory requires more robust testing. As a reviewer notes, and as is expected in the current literature on (im)politeness $[5,6,10]$, validation with respect to dialogue corpora is not attempted here. Similarly, the robustness of the semantic model across cultures requires testing, particularly given the issues raised with the claimed universality of the facework analysis (see e.g. [41]). This paper has provided an incomplete picture of a research programme on the semantic analysis of (im)politeness, and other aspects of the picture are outside the scope of this paper - much more remains even to be outlined in future work.

To recapitulate, here it has been argued that speakers use polite forms in order to avoid invoking disgust and impolite forms when they do not mind disgusting others. Argument is made that it is through specification of described events that theory of (im)politeness can unfold partly in the realm of semantics. This may happen without claiming inherent offence or other sentiment in particular forms of language as the sole means of imbuing conversational behavior with politeness or impoliteness. While this does not resolve the extent to which linguistic politeness behaviors can be effectively characterized within semantic theory as opposed to pragmatics; however, it is argued that at least some of linguistic politeness is well-characterized in semantics. A theory of politeness and impoliteness may be expected to provide strong predictions about individual experience; however, scientific theories often diverge from perceptual experience in some respects. Linguistic politeness and impoliteness arise out of offence management, and as with ambiguity in language generally, in which speaker meaning and hearer meaning have ample chance of differing, the offences to be managed may be intended or unintended.

\section{Acknowledgements}

This research is supported by Science Foundation Ireland (Grant 12/CE/I2267) as part of the Centre for Global Intelligent Content (www.cngl.ie) at Trinity 
College Dublin. I am grateful to the anonymous reviewers, who have made very helpful suggestions. Lingering faults in this work are my own.

\section{References}

1. Allan, K., Burridge, K.: Forbidden Words: Taboo and the Censoring of Language. Cambridge University Press (2006)

2. Alpert, G.P., Smith, W.C.: How reasonable is the reasonable man?: Police and excessive force. The Journal of Criminal Law and Criminology 85(2), 481-501 (1994)

3. Borkowska, P., Kleparski, G.: It befalls words to fall down: Pejoration as a type of semantic change. Studia Anglica Resoviensia 47(4), 33-50 (2007)

4. Bousfield, D.: Impoliteness in Interaction. Amsterdam: John Benjamins (2008)

5. Bousfield, D.: Impoliteness in the struggle for power. In: Impoliteness in Language: Studies on its Interplay with Power in Theory and Practice, pp. 127-153. Berlin: Mouton de Gruyter (2008)

6. Bousfield, D., Locher, M. (eds.): Impoliteness in Language: Studies on its Interplay with Power in Theory and Practice. Berlin: Mouton de Gruyter (2008)

7. Brown, P., Levinson, S.: Politeness: Some Universals in Language Usage. Cambridge University Press (1987)

8. Carpenter, B.: The Logic of Typed Feature Structures. Cambridge Tracts in Theoretical Computer Science 32, Cambridge: Cambridge University Press (1992)

9. Culpeper, J.: Reflections on impoliteness, relational work and power. In: D. Bousfield, M. Locher (eds.) Impoliteness in Language: Studies on its Interplay with Power in Theory and Practice, pp. 17-44. Berlin: Mouton de Gruyter (2008)

10. Culpeper, J.: Impoliteness: Using Language to Cause Offense. Cambridge University Press (2011)

11. Davidson, D.: Events as particulars. In: D. Davidson (ed.) Essays on Actions \& Events, pp. 181-187. Oxford: Oxford University Press (1980)

12. Donovan, D.A., Wildman, S.M.: Is the reasonable man obsolete? a critical perspective on self-defense and provocation. Loyola Los Angeles Law Review 14(3), 435-468 (1981)

13. Dowty, D.: Thematic proto-roles and argument selection. Language 67(3), 547-619 (1991)

14. Ekman, P.: Basic emotions. In: T. Dalgleish, M. Power (eds.) Handbook of Cognition and Emotion, pp. 45-60. John Wiley \& Sons (1999)

15. Fernando, T.: Segmenting temporal intervals for tense and aspect. In: Proceedings of the 13th Meeting on the Mathematics of Language, pp. 30-40. Association for Computational Linguistics (2013)

16. Fitch, W.T.: An invisible hand. Nature 449, 665-667 (2007)

17. Fukumura, K., van Gompel, R.P.G.: Producing pronouns and definite noun phrases: Do speakers use the addressee's discourse model. Cognitive Science 36, 1289-1311 (2012)

18. Goffman, E.: The Presentation of Self in Everyday Life. New York: Doubleday (1956)

19. Goffman, E.: Behavior in Public Places: Notes on the Social Organization of Gatherings. Free Press: New York (1963)

20. Goffman, E.: On face-work. In: Interaction Ritual: Essays in Face-to-Face Behavior, pp. 5-45. New Brunswick, NJ: Transaction Publishers (1967). Reprinted 2008 
21. Hoetjes, M., Krahmer, E., Swerts, M.: Do repeated references result in sign reduction? In: N. Miyake, D. Peebles, R.P. Cooper (eds.) Proceedings of the 34th Annual Meeting of the Cognitive Science Society, pp. 461-466 (12)

22. Johnson-Laird, P., Savary, F.: Illusory inferences: A novel class of erroneous deduction. Cognition 71, 191-229 (1999)

23. Kasper, R., Rounds, W.: A logical semantics for feature structures. In: Proceedings of the 24th Annual Meeting of the Association for Computational Linguistics, pp. 257-266. Columbia University, New York, NY (1986)

24. Kelly, D.: Yuck! The Nature and Moral Significance of Disgust. MIT (2011)

25. Kolnai, A.: Disgust. In: B. Smith, C. Korsmeyer (eds.) On Disgust, pp. 29-91. Open Court Press: Chicago (2004 (1929)). Translated by Elisabeth Gombrich, Elizabeth Kolnai and Barry Smith

26. Kolnai, A.: The standard modes of aversion: Fear, disgust and hatred. In: B. Smith, C. Korsmeyer (eds.) On Disgust, pp. 93-108. Open Court Press: Chicago (2004 (1929)). Translated by Elisabeth Gombrich, Elizabeth Kolnai and Barry Smith

27. Lakoff, R.: The logic of politeness; or, minding your p's and q's. In: C. Corum, T.C. Smith-Stark, A. Weiser (eds.) Papers from the Ninth Regional Meeting of the Chicago Linguistic Society, pp. 292-305 (1973)

28. Lascarides, A., Briscoe, T., Asher, N., Copestake, A.: Order independent and persistent typed default unification. Linguistics and Philosophy 19(1), 1-89 (1996)

29. Leech, G.N.: Principles of Pragmatics. Longman: London (1983)

30. Locher, M., Watts, R.: Relational work and impoliteness: Negotiating norms of linguistic behaviour. In: D. Bousfield, M. Locher (eds.) Impoliteness in Language: Studies on its Interplay with Power in Theory and Practice, pp. 77-99. Berlin: Mouton de Gruyter (2008)

31. MacNeill, D.: Growth points cross linguistically. In: J. Nuyts, E. Pederson (eds.) Language and Conceptualization, Language, Culture \& Cognition, pp. 190-212. Cambridge University Press (1997)

32. Orwell, G.: 1984. New York: Signet (1949). Reprinted 1961

33. Portner, P.: The semantics of imperatives within a theory of clause types. In: R. Young (ed.) SALT XIV, pp. 235-252 (2004)

34. Reichenbach, H.: Elements of Symbolic Logic. McMillan (1947)

35. Schnurr, S., Marra, M., Holmes, J.: Impoliteness as a means of contesting power relations in the workplace. In: D. Bousfield, M. Locher (eds.) Impoliteness in Language: Studies on its Interplay with Power in Theory and Practice, pp. 211229. Berlin: Mouton de Gruyter (2008)

36. Sosa, E.: The semantics of imperatives. American Philosophical Quarterly 4(1), 57-64 (1967)

37. Verkuyl, H.J.: A theory of aspectuality. Cambridge Studies in Linguistics. Cambridge University Press (1993)

38. Vogel, C.: Intended and unintended offence. In: S. Bassis, A. Esposito, F.C. Morabito (eds.) Recent Advances of Neural Network Models and Applications, Smart Innovation, Systems and Technologies Volume 26, pp. 395-404. Springer International Publishing (2014)

39. Vogel, C., Villada, B.: Spanish psychological predicates. In: R. Cann, C. Grover, P. Miller (eds.) Grammatical Interfaces in Head-driven Phrase Structure Grammar, pp. 251-66. Stanford: CSLI Publications (2000)

40. Watts, R.J.: Politeness. Cambridge University Press (2003)

41. Yu, M.c.: On the universality of face: evidence from Chinese compliment response behavior. Journal of Pragmatics 35, 1679-1710 (2003) 